\title{
The Influence Of College Experience On Entrepreneurial Intention Among IKBN Students
}

\author{
Nor Hanis Md Salleh, Shamsul Huda Abd Rani ,Donny Abdul Latief \\ School of Business Management, College of Business, Universiti Utara Malaysia, Sintok, Kedah, Malaysia
}

*Corresponding author: shuda@uum.edu.my

\begin{abstract}
The study was conducted using a questionnaire that was distributed to 365 students of IKBN Kuala Perlis. The data obtained from this survey was analysed using the Statistical Package for Social Science (SPSS) 20.0. The descriptive analysis was used to identify the profile of the IKBN Kuala Perlis' students.This study uses probability sampling design that apply unrestricted or simple random sampling where the element of population was known and every element has an equal or non-zero chance of being selected as sample subject. While through regression analysis it proved that, all these variables are significantly influence the entrepreneurial intention among skills-based students.
\end{abstract}

Keywords: College experience, entrepreneurial intention, social support, mentoring, partial least square.

(C) 2016 Penerbit UTM Press. All rights reserved

\subsection{INTRODUCTION}

The development of human capital is the key agenda towards realizing the vision 2020 (Azhar, \& Idris, 2015). Education serves as a medium mover's in shaping civilized and competitive society. Therefore, entrepreneurship education in Malaysia should be implemented as a strategy to increase the number of skilful human capital and encouraging businesses to achieve commercial and industrial community by 2020. The aim of this action is to produce more intellectuals that actively involved in the field of entrepreneurship.

\subsection{LITERATURE REVIEW}

Based on the information and statistical data obtained from the Ministry of Youth and Sports, a total of 20 IKBN were established throughout Malaysia including Sabah and Sarawak. Besides the main focus is given to the proceedings of skills in the field of education courses, these institutions also provide training and entrepreneurship programs to students. This is intended to prepare the students with entrepreneurial mentality and start their own business when they finish their study. Graduate employability become a hot issue and has been regularly discussed. This group can be referring as labour force that will contribute to the economic growth. According to statistics the rate of unemployment among youths is increasing every year (Mokhtar \& Zainuddin, 2011). Until January 2015, the unemployment rate increased to $3.1 \%$, which approximately 442,000 peoples compared $3.0 \%$ in December 2014 which is 432.100 peoples. Total unemployment for November 2014 is 375,100 peoples and 378,200 peoples in October 2014. This statistic shows that Malaysia was facing failure of young adult especially the graduates to get a job every year. This unemployment issues become one of the reasons why government of Malaysia strongly emphasize on the entrepreneurship.

\section{Entrepreneurial Intention}

Entrepreneurial intentions can be described as a person interest in starting a new business. The intention is the creation of attitude, while attitudes act as intermediaries that affect the entrepreneurial intention (Kim-soon et al., 2013). Intentions towards entrepreneurial career are important and act as a starting point for new business and be self-employed (Sadeghi, Mahommadi, Nosrati \& Malekian, 2013). Most of study of entrepreneurial intention was conducted among universities students (non-business students itself or did a comparison between business and non-business students, engineering students, agriculture student). Thus, bring researcher study in different context. This study will focus on vocational and technic students.

\section{Social Support}

Social support related to assess on individuals cognitive and feel the quality of support (Talwar, Kumaraswamy \& Mohd, 2013). Entrepreneurial career choice among individual not only depend on the characteristics, abilities and skills, but also depends on social support (Ucbasaran, Westhead, \& Wright, 2008). Md. \& Mariam (2010), suggested that Social support is an element that can help 
individuals to reduce the amount of stress experienced as well as to help individual cope and dealing with stressful situations. According to Talwar, et al., (2013), social support is associated with neighbours, family, and friends. Meanwhile study by Fan \& Wang (2009), reveal that social supports can be refer to practical methods or expressive resources channelled by social networks, communities, and close friends.

Based on the review of the literature researcher propose the following hypotheses:

H1: College experience influences entrepreneurial intention among IKBN students.

H2: Social support influences entrepreneurial intention among IKBN students.

\subsection{POPULATION AND SAMPLING}

The total number of IKBN student in Malaysia is between 10,000 and 15,000. Due this table did not provide the accurate number of IKBN population, so researcher decided to choose the closest amount which is 15,000 of population. This is in the line with Sekaran et al., 2009 where the more representative of the population the sample is, the more generalizable are the findings of the research.Thus, 375 samples are needed to represent a total of IKBN student population in Malaysia in order to get more accurate result. The unit analysis of this study is an individual which is students.

\subsection{ANALYSIS AND RESULTS}

Researchers use the software Statistical Package for the Social Sciences (SPSS Version 2.0) to analyse the data. Through descriptive analysis, correlation and regression, the data will be tested for the purpose of analysing the relationship between the independent variable and the dependent variable.

\subsection{FINDINGS}

\section{College Experience Influences The Entrepreneurial Intention Among IKBN Students}

Table 1 shows the result of liner regression analysis for the college experience as an influence factor on entrepreneurial intention. The results shows that the college experience was significantly contribute to the entrepreneurial intention where the $p=.000$ is less than the value of alpha $(.00<.05)$. Regression test showed a significant relationship where college experience significantly affects entrepreneurial intention. The value of $\mathrm{R}^{2}\left(\mathrm{R}^{2}=0.285\right)$ contributes $28.5 \%$ towards entrepreneurial intention among IKBN students. Meanwhile, the value of coefficient (unstandardized Coefficients) or $\beta=0.619$ is show the influence of college experience on entrepreneurial intention. When the score for college experience goes up a unit, the score for entrepreneurial intention will also increase up to 0.619 units.

Table 1 Regression analysis of the college experience and entrepreneurial intention

\section{Coefficients $^{\mathrm{a}}$}

\begin{tabular}{|c|c|c|c|c|c|}
\hline \multirow[t]{2}{*}{ Model } & \multicolumn{2}{|c|}{ Unstandardized Coefficients } & \multirow{2}{*}{$\begin{array}{l}\text { Standardized } \\
\text { Coefficients }\end{array}$} & \multirow[t]{2}{*}{$\mathrm{t}$} & \multirow[t]{2}{*}{ Sig. } \\
\hline & B & Std. Error & & & \\
\hline (Constant) & 1.450 & .186 & & 7.779 & .000 \\
\hline College Experience & .619 & .051 & .536 & 12.155 & .000 \\
\hline
\end{tabular}

\section{Social Support Influences Entrepreneurial Intention Among IKBN Students}

Table 2 shows the result of liner regression analysis for the social support as an influence factor towards the entrepreneurial intention. The results showed that the college experience was significantly contribute to the entrepreneurial intention where the $p=.000$ is less than the value of alpha $(.00<.05)$. This result showed a significant relationship where social support significantly affects entrepreneurial intention. The value of $\mathrm{R}^{2}\left(\mathrm{R}^{2}=0.274\right)$ contributes $27.4 \%$ towards entrepreneurial intention among IKBN students. Meanwhile, the value of coefficient (unstandardized Coefficients) or $\beta=0.575$ shows the influence of social support on entrepreneurial intention. When the score for social support goes up a unit, the score for entrepreneurial intention will also increase up to 0.575 units. 
Table 2 Regression analysis of the social support and entrepreneurial intention

\section{Coefficients $^{\mathrm{a}}$}

\begin{tabular}{|c|c|c|c|c|c|}
\hline \multirow[t]{2}{*}{ Model } & \multicolumn{2}{|c|}{ Unstandardized Coefficients } & Standardized & \multirow[t]{2}{*}{$\mathrm{t}$} & \multirow[t]{2}{*}{ Sig. } \\
\hline & B & Std. Error & Beta & & \\
\hline (Constant) & 1.606 & .178 & & 8.998 & .000 \\
\hline Social Support & .575 & .049 & .526 & 11.833 & .000 \\
\hline
\end{tabular}

\subsection{DISCUSSION AND CONCLUSION}

This study found that the college experience was significantly influence the entrepreneurial intention among IKBN students. This findings was supported by Pace (1984), he found that college is responsible for many things in stimulating the student development and learning. This finding also in line with Shiri et al., (2012), where the college environment conditions become one of important factor that can affect the experience either strengthen or weaken student to become an entrepreneur. This findings also supported by Anderson (2011), in her studies claimed that university environment may influences the student's life and development in future. The results showed that the social support was significantly influence the entrepreneurial intention. This finding explained that the social support will affect someone in making decision to become an entrepreneur. This finding supported by Ucbasaran, et al., (2008), their study found that the entrepreneurial career choice among individual not only depend on the characteristics, abilities and skills, but also depends on social support .

\subsection{RECOMMENDATION FOR FUTURE RESEARCH}

The similar studies also can be conducted on former students or alumni of IKBN to see either some of them become entrepreneurs or not. Other than that the number of samples also can be increased so that researchers can see the trend of entrepreneurship among students in a wider context.

\section{References}

Anderson, A. R. (2011). The University's Role In Developing Chinese Entrepreneurship. Journal of Chinese Entrepreneurship, 3(3), 175-184.

Fan, W., \& Wang, Z. M. (2009). Confirmatory Factor Aanalysis of Entrepreneurial Intention's Dimension Structure. Chinese Journal of Ergonomics, 1, 005.

Henderson, R., \& Robertson, M. (2000). Who Wants To Be An Entrepreneur? Young Adult Attitudes To Entrepreneurship As A Career. Career Development International, 5(6), 279-287.

Kim-soon, N., Ahmad, A. R., Saberi, A. Z., \& Tat, H. H. (2013). Discriminate Analyses of Motivators and Obstacles on Youth Entrepreneurial Intention, 9(17), 5357.

Md, M., \& Mariam. (2011). CoBLAS: Inculcating Entrepreneurial Culture among Higher Education Institutions' Students. International Journal of Social Science and Humanity, 1(1), 86-91.

Mokhtar, R., \& Zainuddin, Y. (2011). Entrepreneurial Intention of Accounting Students in Malaysian Polytechnics Institutions: A Theory of Planned Behavior Approached. World Business Economics and Finance Conference, 11.

Pace, R. C. (1984). MeasuringTheQualityOfCollegeStudentExperiences. Eric.

Sadeghi, M., Mohammadi, M., Nosrati, M., \& Malekian, K. (2013). The Role of Entrepreneurial Environments in University Students Entrepreneurial Intention. World Applied Programming, 3(8), 361-366.

Sekaran, U., R. Bougie, (2009), ResearchMethod for Business: A Skill-Building Approach., $5^{\text {th }}$ edition, United Kingdom: JohnWiley \& Sons Ltd.

Shiri, N., Mohammadi, D., \& Hosseini, S. M. (2012). Entrepreneurial Intention of Agricultural Students: Effects of Role Model, Social Support, Social Norms and Perceived Desirability. Archives of Applied, 4(2), 892-897.

Talwar, P., Kumaraswamy, N., \& Ar, M. F. (2013). Perceived Social Support, Stress and Gender Differences among University Students : A Cross Sectional Study.

Ucbasaran, D., Westhead, P., \& Wright, M. (2008). Opportunity identification and pursuit: does an entrepreneur's human capital matter?. Small Business Economics, $30(2), 153-173$ 